\title{
Fragmentation of Benzylpyridinium "Thermometer" Ions and Its Effect on the Accuracy of Internal Energy Calibration
}

\author{
Konstantin V. Barylyuk, Konstantin Chingin, Roman M. Balabin, and \\ Renato Zenobi \\ Department of Chemistry and Applied Biosciences, ETH Zürich, Zürich, Switzerland
}

Electrospray ionization mass spectrometry (ESI-MS) is a powerful analytical method to study biomolecules and noncovalent complexes. The prerequisite for their intact observation is soft ionization. In ESI, the internal energy of ions is primarily influenced by collisional activation in the source. The survival yield method is frequently used to probe the energy deposition in ions during the electrospray process. In the present work, we investigate the fragmentation pathways of para-substituted benzylpyridinium ions, the most widely used "thermometer ions" in the survival yield method. In addition to the C-N bond cleavage, alternative fragmentation channels were found for the compounds studied. We consider these pathways to result from intramolecular rearrangements. The effect of these additional fragments on the accuracy of the internal energy calibration is estimated for both collision-cell and in-source collision-induced dissociation (CID). Altogether, results presented suggest that a correction of the energy scale is necessary for the method based on benzylpyridinium ions to precisely quantify ion internal energies. (J Am Soc Mass Spectrom 2010, 21, 172-177) (C 2010 American Society for Mass Spectrometry

$\mathrm{E}$ lectrospray ionization mass spectrometry (ESIMS) [1] is widely used to characterize various species, from small organic compounds [2] to large supramolecular assemblies of biopolymers [3]. In the ESI source, small charged droplets containing dissolved analyte are produced at atmospheric pressure. As the droplets migrate along a voltage gradient to the low-pressure region of the mass spectrometer, solvent evaporates, releasing unsolvated ions. Ions produced in the ion source undergo collisions with ambient gas molecules and thereby accumulate internal energy. Such collisional activation often results in fragmentation and/or rearrangement of ions $[4,5]$. The effect is more pronounced for weak interactions, such as those involved in noncovalent complexes, which are widely studied by ESI-MS [5]. In addition, for instruments with restricted MS/MS capabilities, so-called in-source CID is frequently the only way to obtain structural information on the parent ions. In-source CID strongly depends on instrument parameter settings and experimental conditions, thus resulting in poor reproducibility of the MS/MS spectra [5]. Internal energy deposition in ions generally affects the mass spectra. It is therefore important to control the ion internal energy for many applications, such as optimizing the molecular ion abundance, structure deter-

Address reprint requests to Professor R. Zenobi, Department of Chemistry and Applied Biosciences, ETH Zürich, ETH Hönggerberg, HCI E 329, CH-8093 Zürich, Switzerland. E-mail: zenobi@org.chem.ethz.ch mination, differentiation of isomers, $\mathrm{MS}^{n}$ experiments, and in the study of non-ovalent complexes [5].

The survival yield method was introduced to calibrate the internal energy distribution of ions after collisional activation [6, 7]. In this method, compounds with a simple and well known dissociation pattern, so-called thermometer ions, are used to probe the energy uptake due to the activation process. The survival yield is the ratio of the parent ion intensity to the sum of parent and fragment ion intensities in the mass spectrum. It is assumed that all ions that have an internal energy above some critical energy $\left(E_{0}\right)$ undergo dissociation, while all other ions with an internal energy lower than $E_{0}$ do not dissociate. The survival yield is equal to the fraction of ions that have energy below $E_{0}$. This method has often been applied for the evaluation of the internal energy distribution of ions produced by electrospray ionization $[8,9]$.

Several compounds have been introduced as thermometer ions, e.g., transition-metal carbonyl complexes [7], tetraethylsilane ions [7, 10], and substituted benzylpyridinium salts [11]. Benzylpyridinium ions are believed to have a very simple fragmentation pattern, which is an important prerequisite for thermometer ions $[5,11]$. The cleavage of the only $\mathrm{C}-\mathrm{N}$ bond between the benzyl and pyridyl moieties gives rise to neutral pyridine and a substituted benzylium cation (Scheme 1):

The critical energy of benzylpyridinium ions varies depending on the type and the position of the substituent on the benzyl moiety $[5,11]$. Due to the presumed 
<smiles>[R]c1ccc([CH2+])cc1</smiles>

Scheme 1

simplicity of their fragmentation pattern, these compounds have become very popular as thermometer ions and have been used for a number of mass spectrometry applications [12-14]. Benzylpyridinium ions have been used for internal energy calibration of ions produced in both ESI [8] and MALDI [15] sources.

Recent findings, however, contest the validity of the approach based on the simple mechanism shown in Scheme 1. In particular, the possibility of additional reactions involving benzylpyridinium ions was demonstrated [16-18]. In the work of Gabelica et al. [16], the addition of acetonitrile to benzyl cation was observed, and the kinetics of this ion-molecule reaction was studied. The rearrangement of benzyl cations into stable tropylium cations was investigated both experimentally and by theoretical calculations by Zins et al. [17] and earlier by Katritzky et al. [18]. A theoretical model, which was introduced to describe the connection between the survival yield and the internal energy distribution focuses on the $\mathrm{C}-\mathrm{N}$ bond cleavage in benzylpyridinium ions $[5,8,11]$. Alternative reaction pathways can, of course, compromise the reliability of the internal energy calibration, but their characteristic kinetic con- stants and activation energies are usually not taken into account [19].

In the present work, we investigate the fragmentation pathways of benzylpyridinium ions in both insource and collision-cell CID experiments performed on two different mass spectrometers. Alternative fragmentation pathways were found, and their effect on the ion internal energy calibration was assessed. We suggest that these pathways result from intramolecular rearrangement. Although the possibility of rearrangement reaction is known for benzylium cations [17, 18], the additional fragments formation has not previously been reported and characterized.

\section{Experimental}

\section{Materials}

Benzylpyridinium salts were kindly provided by $\mathrm{V}$. Gabelica and E. De Pauw (University of Liège) and were used without further purification. Stock solutions $\left(1 \mathrm{mg} \mathrm{mL}{ }^{-1}\right)$ of 7 para-substituted salts (Table 1$)$ were prepared individually in water and then diluted 100fold with methanol/water (1:1 vol/vol). For mass calibration, a NaI (puriss; Fluka Chemie AG, Buchs Switzerland) solution in 2-propanol/water (1:1 vol/vol) at a concentration of $2 \mathrm{mg} \mathrm{mL}^{-1}$ was used. Methanol and 2-propanol (HPLC grade $\geq 99.9 \%$ ) were purchased from Fluka Chemie AG. Deionized water was available in-house at ETH.

Table 1. Fragments identified in CID experiments on benzylpyridinium ions

\begin{tabular}{|c|c|c|c|c|c|c|}
\hline \multirow[b]{2}{*}{$\mathrm{R}$} & \multirow{2}{*}{$\begin{array}{c}E_{0}\left(\mathrm{kcal} \mathrm{mol}^{-1}\right) \text { calculated by } \\
\mathrm{AM}^{\mathrm{a}}\end{array}$} & \multirow{2}{*}{$\begin{array}{c}E_{0}\left(\mathrm{kcal} \mathrm{mol}^{-1}\right) \text { calculated by } \\
\text { B3LYP/6-311+ } \mathrm{G}^{\mathrm{b}}\end{array}$} & \multirow{2}{*}{$\begin{array}{r}{[\mathrm{M}]^{+}} \\
\mathrm{m} / \mathrm{z}\end{array}$} & \multirow{2}{*}{$\begin{array}{c}{ }^{[\mathrm{M}-79]^{+}} \\
\mathrm{m} / \mathrm{z}\end{array}$} & \multicolumn{2}{|c|}{ Additional fragments } \\
\hline & & & & & Exact mass & Molecular formula \\
\hline \multirow[t]{4}{*}{$p-\mathrm{NO}_{2}$} & 54.2 & 59.3 & 215 & 136 & 169.0887 & $\mathrm{C}_{12} \mathrm{H}_{11} \mathrm{~N}$ \\
\hline & & & & & 106.0419 & $\mathrm{C}_{7} \mathrm{H}_{6} \mathrm{O}$ \\
\hline & & & & & 90.0474 & $\mathrm{C}_{7} \mathrm{H}_{6}$ \\
\hline & & & & & 78.0471 & $\mathrm{C}_{6} \mathrm{H}_{6}$ \\
\hline$p-\mathrm{CN}$ & 48.4 & 55.6 & 195 & 116 & 89.0375 & $\mathrm{C}_{7} \mathrm{H}_{5}$ \\
\hline \multirow[t]{3}{*}{$p-\mathrm{CH}_{3}$} & 40.8 & 44.4 & 184 & 105 & 103.0542 & $\mathrm{C}_{8} \mathrm{H}_{7}$ \\
\hline & & & & & 79.0542 & $\mathrm{C}_{6} \mathrm{H}_{7}$ \\
\hline & & & & & 77.0382 & $\mathrm{C}_{6} \mathrm{H}_{5}$ \\
\hline \multirow[t]{2}{*}{$p-\mathrm{F}$} & 43.1 & 48.0 & 188 & 109 & 89.0402 & $\mathrm{C}_{7} \mathrm{H}_{5}$ \\
\hline & & & & & 83.0300 & $\mathrm{C}_{5} \mathrm{H}_{4} \mathrm{~F}$ \\
\hline \multirow[t]{2}{*}{$p-\mathrm{Cl}$} & 43.8 & 47.3 & 204 & 125 & 99.0000 & $\mathrm{C}_{5} \mathrm{H}_{4} \mathrm{Cl}$ \\
\hline & & & & & 89.0386 & $\mathrm{C}_{7} \mathrm{H}_{5}$ \\
\hline \multirow[t]{6}{*}{$p$-tBu } & - & 42.6 & 226 & 147 & 132.0935 & $\mathrm{C}_{10} \mathrm{H}_{12}$ \\
\hline & & & & & 119.0856 & $\mathrm{C}_{9} \mathrm{H}_{11}$ \\
\hline & & & & & 117.0701 & $\mathrm{C}_{9} \mathrm{H}_{9}$ \\
\hline & & & & & 107.0858 & $\mathrm{C}_{8} \mathrm{H}_{11}$ \\
\hline & & & & & 105.0700 & $\mathrm{C}_{8} \mathrm{H}_{9}$ \\
\hline & & & & & 91.0544 & $\mathrm{C}_{7} \mathrm{H}_{7}$ \\
\hline \multirow[t]{3}{*}{$p-\mathrm{OCH}_{3}$} & 34.8 & 35.6 & 200 & 121 & 106.0405 & $\mathrm{C}_{7} \mathrm{H}_{6} \mathrm{O}$ \\
\hline & & & & & 91.0535 & $\mathrm{C}_{7} \mathrm{H}_{7}$ \\
\hline & & & & & 77.0385 & $\mathrm{C}_{6} \mathrm{H}_{5}$ \\
\hline
\end{tabular}

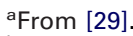

${ }^{\text {b }}$ See the Experimental section.

'Deduced from exact masses of the fragments. 


\section{Mass Spectrometry}

Mass spectrometry experiments were performed on two commercial electrospray ionization (ESI) instruments, a Fourier transfer ion cyclotron resonance (FT-ICR) instrument (Varian/Ion Spec, Lake Forest, CA, USA) and a hybrid quadrupole-time-of-flight (Q-TOF) mass spectrometer (QTOF Ultima; Micromass, Manchester, UK). Both instruments have the same ion source interface, a so-called Z-spray source (Micromass). An automated chip-based nanoESI robot (NanoMate model 100; Advion Biosciences, Ithaca, NY, USA) was used for ion generation on the Q-TOF mass spectrometer. A voltage of $1.3 \mathrm{kV}$ was applied to the chip nozzle, and a 5 bar backing pressure was used to assist the sample flow. The distance to the sampling cone was adjusted to optimize the spray. The sample flow was maintained at $200 \mathrm{~nL} \mathrm{~min}{ }^{-1}$. In FT-ICR measurements, a conventional electrospray configuration was used. The capillary voltage was $4 \mathrm{kV}$, no auxiliary gas was applied, and the sample flow was maintained at $2 \mu \mathrm{L}$ $\min ^{-1}$.

For both instruments, the ion source temperature was maintained at $60^{\circ} \mathrm{C}$ for efficient desolvation, but to avoid thermal dissociation of analyte ions. On the Q-TOF, the sampling cone voltage was varied in the range of $80-240 \mathrm{~V}$ during in-source CID experiments and was kept at $50 \mathrm{~V}$ for MS/MS measurements. The voltage on the first ion guide was kept at $40 \mathrm{~V}$. The transmission of ions through the quadrupole was optimized for the range of $m / z 50-300$. On the FT-ICR, the sampling cone voltage was varied in the range of 30-100 $\mathrm{V}$ and the extractor cone voltage was kept at $10 \mathrm{~V}$.

Collision-induced dissociation (CID) was used in $\mathrm{MS}^{n}$ experiments. On the Q-TOF, ions were activated inside a hexapole collision cell, while sustained offresonance irradiation (SORI) [20, 21] was applied to activate ions inside FT-ICR trap. Argon was used as collision gas. On the Q-TOF, the collision energy offset was varied from 2 to $20 \mathrm{eV}$. In case of in-source CID experiments, a typical collision energy setting of $10 \mathrm{eV}$ was used for optimal ion transmission and sensitivity. In SORI-CID experiments, the frequency offset was varied in the range of $600-3000 \mathrm{~Hz}$ and an activation amplitude of 1-5 V was used; a pulse duration of $0.5 \mathrm{~s}$ was used. The mass spectra acquisition time was $1 \mathrm{~s}$ for both instruments.

\section{Data Processing for Calibrating Ion Internal Energies}

In-source CID and MS/MS spectra of $p$-substituted benzylpyridinium obtained from the QTOF Ultima instrument were used to evaluate the internal energy distribution of ions [22]. Briefly, for each data point, mass spectra were accumulated for $10 \mathrm{~s}$ (MassLynx 4.0; Waters, Manchester, UK). The intensities of precursor and fragment ion peaks were used to calculate the survival yield. Calculated survival yield values were averaged over the number of iterations and plotted against the critical energy of the corresponding benzylpyridinium ion fragmentation according to Scheme 1. The resulting data points were fitted with a Boltzmann equation model with OriginPro 8 (OriginLab Corp., Northampton, MA, USA). The internal energy distribution was obtained by calculating the derivative of the Boltzmann distribution. Mean internal energy values were plotted against the variable experimental parameters (cone voltage or collision energy) followed by linear fitting to obtain the ion internal energy calibration.

Critical energies (Table 1) of benzylpyridinium ions were calculated at the B3LYP/6-311+G(2d,p) level of theory (up to 579 basis functions) using B3LYP/631G(d) optimized geometries. All calculations were performed with Gaussian 03 (Gaussian Inc., USA) [23]. The expected uncertainty of this treatment is $\sim 10 \mathrm{kcal}$ $\mathrm{mol}^{-1}$, which is a factor of 1.5-2 lower than that of the AM1 model [24, 25].

\section{Results and Discussion}

The fragmentation of 7 para-substituted benzylpyridinium ions was studied with two different mass spectrometers, a Q-TOF and a FT-ICR. Table 1 summarizes the results for CID experiments. For all the compounds examined, additional fragments were observed besides the major fragment ion $[\mathrm{M}-79]^{+}$corresponding to the loss of neutral pyridine (Scheme 1). Exact mass measurements were performed to determine the molecular formulae of the additional fragments (Table 1). Figure 1 shows tandem mass spectra ( $a$ and $b$ ) and in-source CID mass spectra (c and $\mathrm{d}$ ) of $p$-cyanobenzylpyridinium recorded on the FT-ICR instrument. At low collision (a)

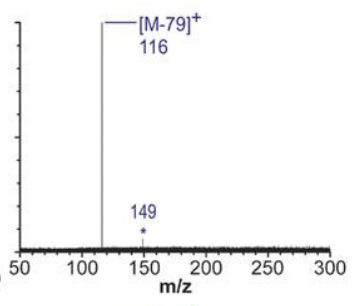

(b)

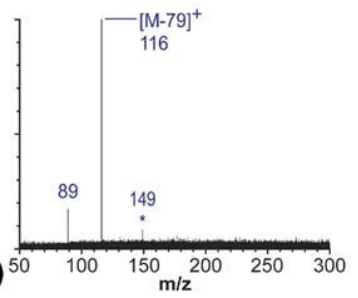

(c)

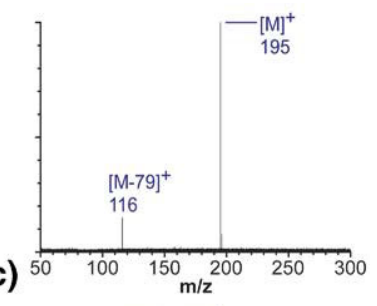

(d)

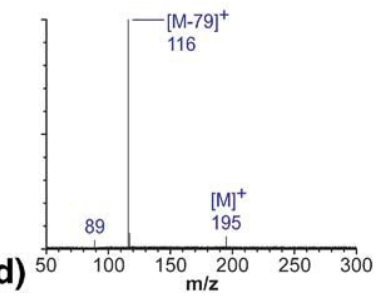

Figure 1. CID fragmentation spectra of para-cyanobenzylpyridinium ion acquired on the FT-ICR. (a) SORI-CID, excitation voltage $2 \mathrm{~V}$; (b) SORI-CID, excitation voltage $4 \mathrm{~V}$; (c) in-source CID, cone voltage $40 \mathrm{~V}$; (d) in-source CID, cone voltage $80 \mathrm{~V}$. Precursor and fragment ion peaks are annotated with $\mathrm{m} / \mathrm{z}$ values, and the precursor ion and benzylium fragment peaks are marked with $[\mathrm{M}]^{+}$and $[\mathrm{M}-79]^{+}$, respectively. ${ }^{*}$ Phthalate fragment $\mathrm{m} / z$ 149, a common ion source contaminant [30], which did not interfere with the result of experiment. 
energy or cone voltage, the parent ion $[\mathrm{M}]^{+}(\mathrm{m} / \mathrm{z}$ 195) and benzylium fragment $[\mathrm{M}-79]^{+}(\mathrm{m} / \mathrm{z} 116)$ were predominant (Figure 1a and c). When increasing the ion activation, the intensity of the $[\mathrm{M}]^{+}$peak went down, while the intensity of the $[\mathrm{M}-79]^{+}$peak grew, yet another fragment ion peak at $m / z \quad 89$ was observed (Figure $1 \mathrm{~b}$ and $\mathrm{d}$ ). Most other compounds featured a similar behavior, differing only in the number of fragments with their characteristic energies of appearance. In the case of $p$-nitrobenzylpyridinium (Figure 2), two additional fragment peaks at $m / z 169$ and 106 were registered along with $[\mathrm{M}]^{+}(m / z 215)$ and $[\mathrm{M}-79]^{+}$ $(m / z 136)$, even at low activation energies (Figure $2 \mathrm{a}$ and c). Two more fragment peaks at $m / z 90$ and 78 showed up at higher values of activation parameter (Figure $2 b$ and $\mathrm{d}$ ). The critical energy $E_{0}$ for $\mathrm{C}-\mathrm{N}$ bond cleavage between the benzyl and pyridyl moieties is relatively high for $p$-nitrobenzylpyridinium, since the strong electron-withdrawing effect of the $\mathrm{NO}_{2}$ group in the para-position destabilizes the benzylium cation. Alternative unimolecular reactions may have activation energies that are similar or equal to $E_{0}$ and can therefore proceed in parallel with the typical fragmentation according to Scheme $\mathbf{1}$.

The masses of the additional fragments (except for the case of $p$-nitrobenzylpyridinium) are below [M $79]^{+}$(Table 1 ). These ions cannot be produced easily by direct bond cleavage of benzylpyridinium. We therefore suggest that a rearrangement of either parent or benzylium ion takes place first, followed by an alternative fragmentation. The rearrangement of the benzylium cation into a stable tropylium cation was previously studied experimentally and by quantum chemical

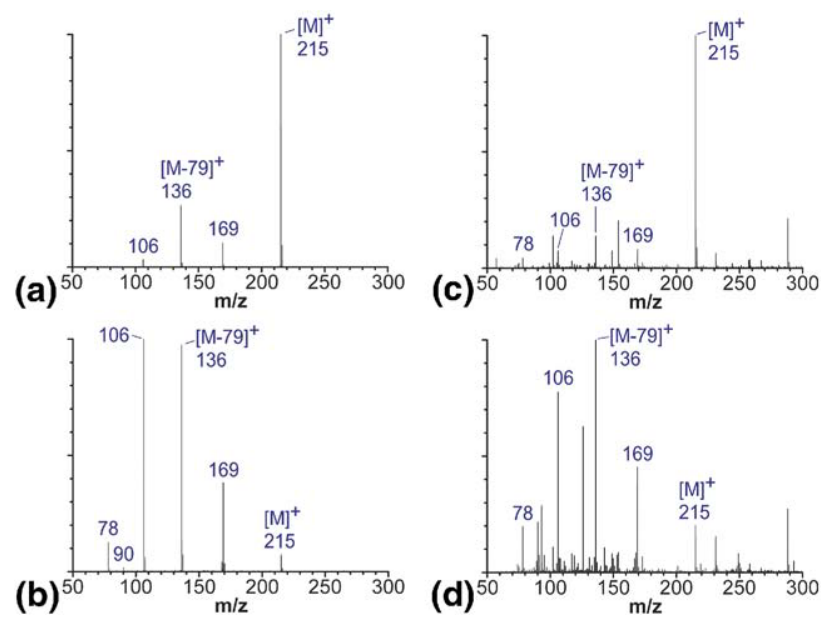

Figure 2. CID fragmentation spectra of para-nitrobenzylpyridinium ion acquired on the Q-TOF instrument. (a) Collision cell CID, collision energy $12 \mathrm{eV}$; (b) collision cell CID, collision energy 22 $\mathrm{eV}$; (c) in-source CID, cone voltage $140 \mathrm{~V}$; (d) in-source CID, cone voltage $180 \mathrm{~V}$. Precursor and fragment ion peaks are annotated with $\mathrm{m} / \mathrm{z}$ values, and the precursor ion and benzylium fragment peaks are marked with $[\mathrm{M}]^{+}$and $[\mathrm{M}-79]^{+}$, respectively. Peaks that are not annotated correspond to common ion source contaminants and sample impurities [30]. These impurities did not interfere with the result of experiment. calculations [17, 18]. In the present study, we also observed that additional fragment ions can be produced in the $\mathrm{MS}^{3}$ experiment on $[\mathrm{M}-79]^{+}$(data not shown), supporting the mechanism of benzylium cation rearrangement. The results of SORI-CID experiments in the FT-ICR instrument, however, suggest yet another mechanism. In these experiments, the fragmentation of parent ion $[\mathrm{M}]^{+}$gave rise to the major and the additional fragments simultaneously (Figure 1b). In SORICID, cyclotron motion of precursor ions is excited by a near resonance RF pulse. Multiple collisions of thus accelerated ions with buffer gas molecules induce the dissociation. SORI-CID is a selective ion activation method, in which only ions of a particular $m / z$ value are dissociated. Fragments produced do not dissociate further [20, 21]. Thus, all the fragments observed must originate from the parent ion. We can therefore conclude that several fragmentation pathways are open upon activation of benzylpyridinium ions and that the cleavage of $\mathrm{C}-\mathrm{N}$ bond between pyridyl and benzyl moieties is the lowest energy fragmentation channel in most cases.

In view of our findings, the question arises whether the model proposed by De Pauw $[5,8,11]$ needs to be extended to accurately describe the ion internal energy distribution of benzylpyridinium ions, and whether benzylpyridinium ions are an ideal choice as thermometer ions. The theoretical model by De Pauw describes the internal energy distribution for the limit where $\mathrm{C}-\mathrm{N}$ bond cleavage is the one and only fragmentation reaction taking place. However, as shown here for benzylpyridinium ions, several reactions proceed simultaneously or sequentially. Each of these reactions is characterized by its own kinetic and thermodynamic parameters that should be taken into account. In the strict sense, De Pauw's model is incomplete, because it does not take into account these additional fragmentation pathways of the benzylpyridinium ions.

We therefore carried out lower-bound estimates of the effect of these additional fragmentation channels on the ion internal energy according to the De Pauw's theoretical model. Since the formation of the $[\mathrm{M}-79]^{+}$ fragment is the lowest energy fragmentation channel and all other reactions proceed at higher activation energy, the loss of neutral pyridine is the dominant reaction at an energy equal to $E_{0}$. To simplify the analysis, we assume that additional fragments are produced by reactions having the same kinetic and thermodynamic parameters as the major one. In this case, the system has only one explicit parameter $\left(E_{0}\right)$, and De Pauw's theoretical model can still be applied. The only difference is that the survival yield must be calculated, taking into account the entire set of fragments. At each ion activation parameter (collision energy or cone voltage) value, the mean internal energy of the ions can be derived and used to build a calibration plot.

Figure 3 shows the relationship between ion mean internal energy and ion activation parameter obtained with Q-TOF. Ion internal energies were calculated taking into account only the $[\mathrm{M}-79]^{+}$intensity (filled 

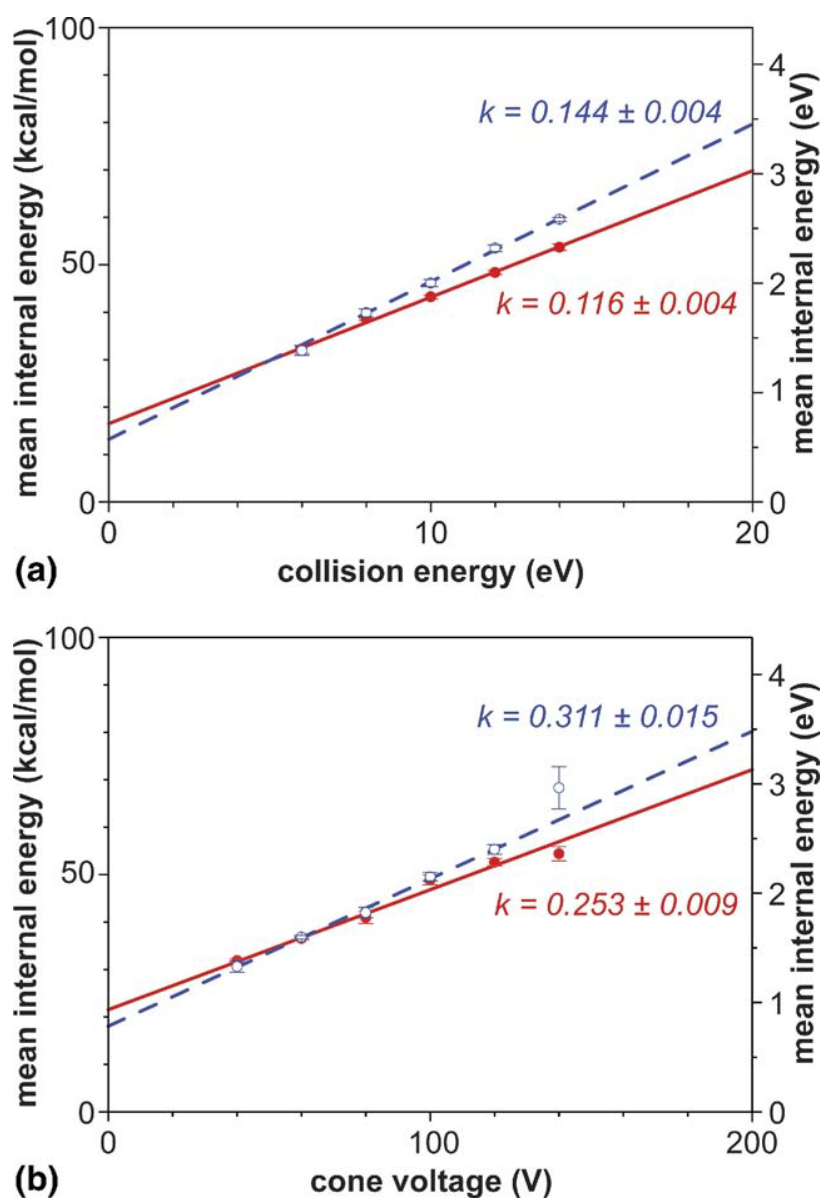

Figure 3. Ion internal energy calibration evaluated for (a) collision cell and (b) in-source CID using the Q-TOF mass spectrometer. Internal energy distributions were derived from the survival yields calculated considering the intensity of only the $[\mathrm{M}-79]^{+}$ fragments (filled red dots, solid red line) and when intensities of all fragment ions were taken into account (open blue dots, dashed blue line). Slopes with standard deviation for the linear fitting are shown; (b) $[k]=\mathrm{kcal} \mathrm{mol}^{-1} \mathrm{~V}^{-1}$.

dots) or, alternatively, all fragment ion intensities (open dots). A linear dependence is clearly observed. All experimental data points lie within the $95 \%$ confidence interval (not shown) of the corresponding linear fits. The slope of the straight line characterizes the increase of the ion internal energy with increasing collision energy (Figure 2a) or cone voltage (Figure 2b). The picture obtained for in-source CID (Figure $2 b$ ) is very similar to the case of collision cell CID (Figure 2a). This indicates the similarity of CID processes taking place in the ESI source and collision cell. In both cases we deal with multiple collisions, i.e., ions undergo a number of low-energy collisions with neutral gas molecules before dissociation. The slope of the linear fit corresponding to the ion internal energy calculated based on a canonical fragmentation scheme (Figure 3, solid line) is lower than that of the line representing the case of multiple fragmentation pathways (Figure 3, dashed line). When increasing the ion activation (cone voltage or collision energy) the mean internal energy of ions grows faster than the canonical model predicts. This difference is real and reliable for two reasons: first, the $k$ values characterizing the slopes of linear fits differ significantly (Figure 3), and second, the $95 \%$ confidence intervals for the two linear fits do not include a significant number of data points obtained with the alternative model.

In reality, the actual critical energies for the additional fragmentation reactions should be higher than that for the major mechanism, neutral pyridine loss, which is preferentially observed at low activation. In other words, a higher internal energy needs to be deposited into the system for the alternative dissociation mechanisms to effectively compete with the major fragmentation. The maximum ion internal energy distribution should therefore shift towards a higher value. The ion internal energy should therefore deviate even more from the one predicted with the canonical model.

The lower-bound estimation proposed here, although rough and oversimplified, unambiguously shows that additional fragmentation pathways cannot be ignored when probing the internal energy distribution of ions produced in electrospray. The behavior of benzylpyridinium ions in the CID process is more complex. Every reaction proceeding in the system is characterized by its own kinetic and thermodynamic parameters that should be taken into account. The master equation formalism can be used to precisely describe multichannel unimolecular reactions [26, 27], particularly, dissociation of collision-activated ions [28]. The main source of error in the model will be the presence of reactions exhibiting a reverse activation barrier. Indeed, some fragments observed in the present study may originate from radical-type cleavage reactions and reverse activation barriers may be present in such fragmentation channels. Furthermore, ions of different $\mathrm{m} / \mathrm{z}$ are transmitted with different efficiency through the mass spectrometer. Since focusing electrodes are usually optimized to transport precursor ion with the highest efficiency, the transmission capacity for lighter fragment ions can be lower. Moreover, collisions with neutral gas molecules result in more efficient scattering for lighter ions. All these effects are difficult to account for and control precisely. As can be seen from the above, there are many questions in this field left for future investigations.

\section{Conclusions}

In the present study, additional fragmentation channels of the most commonly used thermometer ions, benzylpyridinium ions, were found. The contribution of these additional fragments to the calculated ion internal energy was estimated. This estimation provides clear evidence that additional fragments compromise the accuracy of the ion internal energy calibration. 


\section{Acknowledgments}

The authors acknowledge financial support for this work from the Swiss National Science Foundation (grant 200020_124663). They are grateful to Professor Edwin De Pauw and Dr. Valérie Gabélica for the gift of benzylpyridinium salts, and to ETH Zürich Mass Spectrometry Service for assistance in exact mass measurements.

\section{References}

1. Fenn, J. B.; Mann, M.; Meng, C. K.; Wong, S. F.; Whitehouse, C. M. Electrospray Ionization for Mass-Spectrometry of Large Biomolecules. Science 1989, 246, 64-71.

2. Rosenberg, E. The Potential of Organic (Electrospray- and Atmospheric Pressure Chemical Ionization) Mass Spectrometric Techniques Coupled to Liquid-Phase Separation for Speciation Analysis. J. Chromatogr. A 2003, 1000, 841-889.

3. van den Heuvel, R. H.; Heck, A. J. R. Native Protein Mass Spectrometry: From Intact Oligomers to Functional Machineries. Curr. Opin. Chem. Biol. 2004, 8, 519-526.

4. Shukla, A. K.; Futrell, J. H. Tandem Mass Spectrometry: Dissociation of Ions by Collisional Activation. J. Mass Spectrom. 2000, 35, 1069-1090.

5. Gabelica, V.; De Pauw, E. Internal Energy and Fragmentation of Ions Produced in Electrospray Sources. Mass Spectrom. Rev. 2005, 24, 566587.

6. Kenttamaa, H. I.; Cooks, R. G. Internal Energy-Distributions Acquired through Collisional Activation at Low and High-Energies. Int. I. Mass Spectrom. Ion Processes 1985, 64, 79-83.

7. Wysocki, V. H.; Kenttamaa, H. I.; Cooks, R. G. Internal EnergyDistributions of Isolated Ions after Activation by Various Methods. Int. J. Mass Spectrom. Ion Processes 1987, 75, 181-208.

8. Collette, C.; De Pauw, E. Calibration of the Internal Energy Distribution of Ions Produced by Electrospray. Rapid Commun. Mass Spectrom. 1998, 12, 165-170.

9. Naban-Maillet, J.; Lesage, D.; Bossee, A.; Glimbert, Y.; Sztaray, J.; Vekey, K.; Tabet, J. C. Internal Energy Distribution in Electrospray Ionization. J. Mass Spectrom. 2005, 40,1-8.

10. Voyksner, R. D.; Pack, T. Investigation of Collisional-Activation Decomposition Process and Spectra in the Transport Region of an Electrospray Single-Quadrupole Mass Spectrometer. Rapid Commun. Mass Spectrom. 1991, 5, 263-268.

11. Derwa, F. de Pauw, E.; Natalis, P. New Basis for a Method for the Estimation of Secondary Ion Internal Energy Distribution In "Soft" Ionization Techniques. Org. Mass Spectrom. 1991, 26, 117-118.

12. Touboul, D.; Jecklin, M. C.; Zenobi, R. Ion Internal Energy Distributions Validate the Charge Residue Model for Small Molecule Ion Formation by Spray Methods. Rapid Commun. Mass Spectrom. 2008, 22, 1062-1068.

13. Lecchi, P.; Zhao, J. H.; Wiggins, W. S.; Chen, T. H.; Yip, P. F.; Mansfield, B. C.; Peltier, J. M. A Method for Monitoring and Controlling Reproducibility of Intensity Data in Complex Electrospray Mass Spectra: A Thermometer Ion-Based Strategy. J. Am. Soc. Mass Spectrom. 2009, 20, 398-410.

14. Nefliu, M.; Smith, J. N.; Venter, A.; Cooks, R. G. Internal Energy Distributions in Desorption Electrospray Ionization (DESI). J. Am. Soc. Mass Spectrom. 2008, 19, 420-427.

15. Greisch, J. F.; Gabelica, V.; Remacle, F.; De Pauw, E. Thermometer Ions for Matrix-Enhanced Laser Desorption/Ionization Internal Energy Calibration. Rapid Commun. Mass Spectrom. 2003, 17, 1847-1854.
16. Gabelica, V.; Lemaire, D.; Laprevote, O.; De Pauw, E. Kinetics of Solvent Addition on Electrosprayed Ions in an Electrospray Source and in a Quadrupole Ion Trap. Int. J. Mass Spectrom. 2001, 210, 113-119.

17. Zins, E. L.; Pepe, C.; Rondeau, D.; Rochut, S.; Galland, N.; Tabet, J. C. Theoretical and Experimental Study of Tropylium Formation from Substituted Benzylpyridinium Species. J. Mass Spectrom. 2009, 44, 12-17.

18. Katritzky, A. R.; Watson, C. H.; Degaszafran, Z.; Eyler, J. R. Kinetics and Mechanism of Nucleophilic Displacements with Heterocycles as Leaving Groups. 26. Collisionally Activated Dissociation of N-Alkylpyridinium Cations to Pyridine and Alkyl Cations in the Gas-Phase. J. Am. Chem. Soc. 1990, 112, 2471-2478.

19. Moonen, F.; Collette, C.; De Pauw, E. On the Determination of the Ion Internal Energy in an Electrospray Source. In NATO Advanced Research Workshop on New Methods for the Study of Molecular Aggregates, Springer: Kananaskis, Canada, 1996.

20. Gauthier, J. W.; Trautman, T. R.; Jacobson, D. B. Sustained OffResonance Irradiation for Collision-Activated Dissociation Involving Fourier-Transform Mass Spectrometry-Collision-Activated Dissociation Technique That Emulates Infrared Multiphoton Dissociation. Anal. Chim. Acta 1991, 246, 211-225.

21. Laskin, J.; Futrell, J. H. Activation of Large Ions in FT-ICR Mass Spectrometry. Mass Spectrom. Rev. 2005, 24, 135-167.

22. Gabelica, V.; Schulz, E.; Karas, M. Internal Energy Build-Up in MatrixAssisted Laser Desorption/Ionization. J. Mass Spectrom. 2004, 39, $579-$ 593.

23. Frisch, M. J.; Trucks, G. W.; Schlegel, H. B.; Scuseria, G. E.; Robb, M. A.; Cheeseman, J. R.; Montgomery, J. A., Jr.; Vreven, T.; Kudin, K. N.; Burant, J. C.; Millam, J. M.; Iyengar, S. S.; Tomasi, J.; Barone, V.; Mennucci, B.; Cossi, M.; Scalmani, G.; Rega, N.; Petersson, G. A.; Nakatsuji, H.; Hada, M.; Ehara, M.; Toyota, K.; Fukuda, R.; Hasegawa, J.; Ishida, M.; Nakajima, T.; Honda, Y.; Kitao, O.; Nakai, H.; Klene, M.; Li, X.; Knox, J. E.; Hratchian, H. P.; Cross, J. B.; Bakken, V.; Adamo, C.; Jaramillo, J.; Gomperts, R.; Stratmann, R. E.; Yazyev, O.; Austin, A. J.; Cammi, R.; Pomelli, C.; Ochterski, J. W.; Ayala, P. Y.; Morokuma, K.; Voth, G. A.; Salvador, P.; Dannenberg, J. J.; Zakrzewski, V. G.; Dapprich, S.; Daniels, A. D.; Strain, M. C.; Farkas, O.; Malick, D. K.; Rabuck, A. D.; Raghavachari, K.; Foresman, J. B.; Ortiz, J. V.; Cui, Q.; Baboul, A. G.; Clifford, S.; Cioslowski, J.; Stefanov, B. B.; Liu, G.; Liashenko, A.; Piskorz, P.; Komaromi, I.; Martin, R. L.; Fox, D. J.; Keith, T.; Al-Laham, M. A.; Peng, C. Y.; Nanayakkara, A.; Challacombe, M.; Gill, P. M. W.; Johnson, B.; Chen, W.; Wong, M. W.; Gonzalez, C.; Pople, J. A. Gaussian 03, Rev. D.01. Gaussian, Inc., Wallingford CT, 2004.

24. Riley, K. E. Op't Holt, B. T.; Merz, K. M. Critical Assessment of the Performance of Density Functional Methods for Several Atomic and Molecular Properties. J. Chem. Theory Computut. 2007, 3, 407-433.

25. Balabin, R. M. Enthalpy Difference Between Conformations of Norma Alkanes: Intramolecular Basis Set Superposition Error (BSSE) in the Case of N-Butane and N-Hexane. J. Chem. Phys. 2008, 129, 164101164105.

26. Troe, J. Theory of Thermal Unimolecular Reactions at Low-Pressures. 1. Solutions of Master Equation. J. Chem. Phys. 1977, 66, 4745-4757.

27. Miller, J. A.; Klippenstein, S. J. Master Equation Methods in Gas Phase Chemical Kinetics. J. Phys. Chem. A 2006, 110, 10528-10544.

28. Drahos, L.; Vekey, K. Masskinetics: A Theoretical Model of Mass Spectra Incorporating Physical Processes, Reaction Kinetics and Mathematical Descriptions. J. Mass Spectrom. 2001, 36, 237-263.

29. Gabelica, V.; De Pauw, E.; Karas, M. Influence of the Capillary Temperature and the Source Pressure on the Internal Energy Distribution of Electrosprayed Ions. Int. J. Mass Spectrom. 2004, 231, 189-195.

30. Guo, X. H.; Bruins, A. P.; Covey, T. R. Characterization of Typical Chemical Background Interferences in Atmospheric Pressure Ionization Liquid Chromatography-Mass Spectrometry. Proceedings of the 53rd Annual Conference of the ASMS Conference; 2005. San Antonio, TX, June, 2005. 